\title{
Recommendations for revising the energy label system for dishwashers: supporting sustainable development and usage through the interaction of energy labels, technical improvements and consumer behaviour
}

\author{
Lena Brunzell $\mathbb{( D )}$ - Roger Renström $\mathbb{D}$
}

Received: 28 March 2019 /Accepted: 28 November 2019/Published online: 11 December 2019

(C) The Author(s) 2019

\begin{abstract}
Historically, domestic chores such as washing dishes were all done by hand. Today it is estimated that $44 \%$ of the households in the EU are equipped with a dishwasher. In this article, we discuss the connections between technical developments, consumer behaviour and the test standard for energy labels. The aim of this study is to provide recommendations for future work that would strengthen the role of the energy label in order to promote the more sustainable technical development of household appliances. Technical developments are compared with the consequences of different consumer behaviour. It was found that technical developments could reduce annual energy use, but depending on the implemented technology, this is often complex and requires additional components. On the other hand, a consumer can easily increase energy usage by $50 \%$ without being aware of doing so, when goods are pretreated, appliances incorrectly loaded, or inappropriate programs selected. Our recommendation is first of all to encourage the use of dishwashers as they consume less energy and water compared with washing up manually. A holistic approach should be taken to updating the energy labelling system. Actual consumer behaviour must be taken into account and, perhaps most impor-
\end{abstract}

L. Brunzell $(\bowtie) \cdot$ R. Renström

Department of Engineering and Chemical Sciences, Karlstad University, SE-651 88 Karlstad, Sweden

e-mail: lena.brunzell@kau.se

R. Renström

e-mail: roger.renstrom@kau.se tantly, as dishwashers are becoming ever more energy efficient, consumers must be educated in using the machines in an environmentally friendly way. We conclude that the energy labelling system is outdated; it must be fundamentally revised and must take into account consumer behaviour.

Keywords Energy label · Household appliances · Pretreatment $\cdot$ Water consumption

\section{Introduction}

The framework set out by the European Council in October 2014, consisting of a domestic target of at least a $40 \%$ reduction of greenhouse gas emissions from 2030 as well as renewable energy and energy efficiency targets of at least $27 \%$, was followed up by the multilateral Paris Agreement in 2015, in which 195 countries agreed to cap global warming at $1.5{ }^{\circ} \mathrm{C}$ between 2010 and 2100. This sends a clear signal to all parts of the community that a move away from fossil fuels to renewable and more efficient energy usage is required (European Commission 2016). According to the IPCC (Edenhofer et al. 2015), the building sector accounted for $25 \%$ of the greenhouse gas emission and $32 \%$ of the total global energy use in 2010. In Sweden, approximately $30 \%$ of the energy used in households comprises household electricity, and of this nearly $25 \%$ is used for laundry, dishes and cooking (Energimyndigheten 2017a).

It is estimated that $44 \%$ of EU households are equipped with a dishwasher, and this would mean that 
there are around 96 million units in use. In 2015, the energy usage from these units was estimated to be $31 \mathrm{TWh} /$ year and the water usage 317 million cubic metres. If no measures are taken, energy use will rise to $40 \mathrm{TWh} /$ year in 2030 , equivalent to 15 million tons $\mathrm{CO}_{2 \mathrm{eq}}$ (European Commission 2018). Ninety-six million units are a considerable number of appliances; however, studies on the environmental impact from domestic chores show that modern household appliances generally use less energy, water and detergent when compared with performing the chores manually (Stamminger et al. 2007; Olsson and Karlsson 2015). According to Richter (2011), a household with a dishwasher uses on average $50 \%$ less energy and $28 \%$ less water per cleaned item compared with households where the dishes are done by hand.

In 1995, the EU directive on energy labelling on household products was launched. The idea was that a clear labelling system would help consumers to find the most energy-efficient appliances from the large assortment available when purchasing a new product. Similarly, manufacturers would be incentivized to develop more energy-efficient products in order to be competitive on the market. This led to good results: refrigerators and freezers now use one-third of the energy they used when the labelling system was launched (Abdessalem and Labidi 2016). A similar development for dishwashers was presented by Bengtsson and Eikevik (2016), where the electricity use of one manufacturer's products was reduced from 3.7 to $1.1 \mathrm{kWh}$ between 1977 and 2003, and water use was reduced from 60 to 9.9 L. This study also indicates that the reduction of electricity and water usage has flattened out due to difficulties in making the traditional washing process even more efficient. New technology will be needed in order to make larger improvements (Bengtsson and Eikevik 2016). In general, manufacturers are restrictive about sharing information with competitors. Their focus is on keeping concepts secret, patenting them and introducing good concepts and ideas as quickly as possible to get products on the market. Existing beliefs about the advantages of buying an energy-efficient product might persuade green consumers to select a product with a better energy label and this belief may be strengthened when energy-efficient products are marketed as being innovative (Ha and Janda 2012).

The energy labelling system is designed to enable people to understand the differences between products, regardless of the language they speak. Energy use is shown using letters and arrows of different lengths and colours. Products with high energy use are labelled with a red arrow and the letter D, while products with low energy use receive a short green arrow with the letter A. A clear labelling system is also well suited to the increasing sales of appliances on the Internet because it makes it easier for consumers to compare a large number of appliances based on online viewing alone. With the introduction of higher ratings, such as A+, Russo et al. (2018) as well as Stadelmann and Schubert (2018) claim that the labels have the potential to become even more effective in persuading consumers to buy more energy-efficient products. There are, however, studies showing that there is a risk that the energy label A becomes the focus of the consumers' assessment and when adding one, two or three plusses, they could interpret all classes as being more or less the same (Ölander and Thøgersen 2014). In 2021, there will be a revision of the energy labelling framework directive changing back to an A to G scale (Energimyndigheten 2019).

According to Boyano et al. (2017), class A was banned for all dishwasher models from December 2016. They also state that $44 \%$ of the sold appliances in Sweden had an energy class of A++ or A+++. This puts Sweden in sixth place of EU countries, while Germany leads with a figure of $65 \%$. Even though the focus of the energy label lies on the purchase choice, Bichler et al. (2015) indicates that clear information regarding the ECO program and the energy label can also affect the users' choice of washing program.

Although the price of electricity changes over time in different countries, the manufacturers' development of more energy-efficient appliances has continued. There is a great consumer demand for products with good energy ratings, which seems to confirm that the group of green consumers is growing. Stadelmann and Schubert (2018), who studied the influence of introducing a new energy label with monetary and lifetime-oriented information that includes energy costs, did not find that this new label affected consumers' purchases more than the EU energy label.

Although dishwashers today are energy efficient, consumer behaviour when washing up has a great effect on their environmental impact, as is frequently reported in the literature (Richter 2010, 2011; Stawreberg and Wikström 2011; Vivian et al. 2011; Conrady et al. 2014; Schmitz and Stamminger 2014; Kim et al. 2015; Pakula and Stamminger 2015; Abdessalem and Labidi 2016; 
Energimyndigheten 2017b). Regarding dishwashers, the problems mainly concern prewashing, the choice of program and the filling grade when washing.

In this article, we discuss the connections between technical developments, consumer behaviour and the test standard for the energy label. We demonstrate the complexity and the relatively small improvements in dishwashers' energy efficiency and water use on a traditional washing cycle that can be achieved through technical developments. We then put these figures in relation to the energy losses that may occur due to consumer behaviour when goods are pre-treated, appliances are incorrectly loaded or inadequate programs are selected. When the energy label is determined, only one of the dishwasher's programs is used. This means that the choice of program may have a significant effect on the energy use of the product. The aim of this study is also to provide recommendations for future work that would strengthen the role of the energy label in order to promote more sustainable technical development of household appliances.

\section{Method}

Two representative dishwashers were chosen for this study and their user manuals were taken from the homepages of the manufacturers Electrolux and Miele (Electrolux 2017, and Miele 2017). Electrolux is low priced and $\mathrm{A}++$, while Miele is high priced and $\mathrm{A}+++$. They represent two different segments of pricing and labelling and are therefore interesting to discuss and compare. Boyano et al. (2017) claim that in 2012, BSH (Bosch, Siemens) was the main player in the European white goods industry. BSH only gives information about energy and water use for the ECO program in their manuals. Electrolux, the second largest player, gives full information as does Indesit, the third largest player. Miele was, according to Boyano et al. (2017), the seventh largest player; they also gives full information. Data found in the manuals were used for calculations and further discussions.

In the earlier cited literature, it is shown that the everyday use of the dishwashers does not correspond to the labelling system. The energy labelling system was therefore further used in this study to determine the differences in yearly energy use between possible technical improvements and different consumer usages of the appliance.
To determine the annual energy use, the energy efficiency index was used according to the regulation from the European Commission (2010) for dishwashers. Table 1 shows the relation between the energy efficiency index and the energy label for dishwashers.

The energy efficiency index was determined from standard procedure tests according to

$E E I=\frac{A E_{c}}{S A E_{c}} \times 100$

where $\mathrm{AE}_{\mathrm{c}}$ is the annual energy consumption of the household appliance and $\mathrm{SAE}_{\mathrm{c}}$ is the standard annual energy consumption of the appliance. When the EEI was determined, the annual energy consumption $\mathrm{AE}_{\mathrm{c}}$ for the dishwasher was determined from a usage of 280 cycles per year, including the power consumption of standby and off mode during 1 year, each of them considering 50\% during which no power management is present.

$$
\begin{aligned}
A E_{c} & =E_{t} \times 280 \\
& +\frac{\left[P_{0} \times \frac{525600-\left(T_{t} \times 280\right)}{2}+P_{t} \times \frac{525600-\left(T_{t} \times 280\right)}{2}\right]}{60 \times 1000}
\end{aligned}
$$

$E_{t}$ is the energy consumption for the standard cycle $(\mathrm{kWh}) ; P_{t}$ is the power in left-on mode for the standard cleaning cycle $(\mathrm{W}) ; P_{o}$ is the power in off mode for the standard cleaning cycle $(\mathrm{W})$; and $T_{t}$ is the program time required for the standard cleaning cycle (minutes). For a dishwasher with a higher capacity than 10 place settings (ps) and a width greater than $50 \mathrm{~cm}$, as used in this study, the standard annual energy consumption, $\mathrm{SAE}_{\mathrm{C}}$, is calculated in $\mathrm{kWh} /$ year according to

$S A E_{c}=7.0 \times p s+378$.

Often dishes are pre-rinsed before they are loaded into the dishwasher. When rinsing the dishes manually, a high water flow would be preferable due to the increased

Table 1 Energy efficiency classes for household dishwashers (European Commission 2010)

\begin{tabular}{ll}
\hline Energy label & Energy efficiency index $(\mathrm{EEI})$ \\
\hline $\mathrm{A}^{+++}$ & $\mathrm{EEI}<50$ \\
$\mathrm{~A}^{++}$ & $50 \leq \mathrm{EEI}<56$ \\
$\mathrm{~A}^{+}$ & $56 \leq \mathrm{EEI}<63$ \\
\hline
\end{tabular}


force from the water. The maximum flowrate is $6 \mathrm{~L} / \mathrm{min}$ if the pressure in the household water system is $50 \mathrm{kPa}$, which is normal in Sweden (Gustavsberg 2017). In order to determine the energy and water demand for pre-rinsing the dishes in this study, a water flow of $5 \mathrm{~L} / \mathrm{min}$ was used in all calculations, irrespective of whether cold or hot water was used. The actual flowrate in kitchen mixers depends on the pressure of the household water system.

\section{Results and discussion}

Energy labelling of dishwashers

On the Swedish market, dishwashers are today rated A+ or higher. Of 100 appliances, 23 were rated $\mathrm{A}+, 37 \mathrm{~A}++$ and $40 \mathrm{~A}+++$, indicating that most of the dishwashers already have the best energy rating. In this study, 13 different manufacturers were represented (PriceRunner Sverige 2019). Compared with the figure of $44 \%$ presented by Boyano et al. (2017), the number of appliances marked with $\mathrm{A}++$ or $\mathrm{A}+++$ seems to have increased in Sweden.

The difference in maximum annual energy consumption for the criteria for different energy labels is shown in Fig. 1. The figure shows that considerable improvements must be made in order to be awarded a better rating, if taking into account the high present standard of the dishwashers on the market. As an example, the annual energy use of the most energy-efficient A+ dishwasher must be reduced by a minimum of $11 \%$ in order to fulfil the criteria of an A+++ label. This corresponds to approximately $0.1 \mathrm{kWh}$ per cycle or $29 \mathrm{kWh}$ per year.

The tests for determining the energy label are performed on a defined dishwashing program according to the standard (European Commission 2010). As a result, the ECO programs are optimised for the labelling test. During the test, only small amounts of food such as egg, oatmeal, spinach and milk are put on the dishes using a brush. The substances are first dried and then burned onto the dishes in an oven resulting in a rather tough soiling before they are loaded into the dishwasher. In any ordinary kitchen, this would be an unusual procedure. Using a brush when soiling the dishes means that the total amount of particles used in the tests is comparatively small compared with normal consumer behaviour. As described by Hubbuch and Goodall (1999), the amount of soil in the test is low and does not correlate with normal consumer behaviour. They also point out that the amount of protein is overestimated in the tests. The dishwashers have good filter systems and hereby a good capacity to rinse off and separate the particles. This capacity should be challenged in the tests in order to increase the relevance of the labelling system and the ECO program.

There is a large number of different programs in an ordinary dishwasher on the market. The differences between the dishwashers' programs are often significant as regards water and energy usage. Two different dishwashers are presented in Tables 2 and 3. The dishwasher from Electrolux, ESF5533LOW, is labelled A++, according to its manual (Electrolux 2017). The dishwasher from Miele has an energy label A+++ (Miele 2017). Both are designed for more than 10 place settings.

\section{Technical developments}

All dishwashers on the market today are rated A+ or better. The technical development of the washing cycle has flattened out, as indicated by Bengtsson and Eikevik (2016), and there are few reported studies on technical improvements to dishwashers in the literature. The largest improvements occur when new technology is introduced, such as heat pumps or absorption materials to improve the drying process. The studies performed by Bengtsson and Eikevik (2016) and Bengtsson et al. (2015) indicate that introducing a complex heat pump system in a dishwasher on the market would result in an improvement of $61 \mathrm{kWh}$ per year. Keeping the annual energy use for the different energy labels in mind, this improvement would lead to a significant improvement in the appliance's energy rating. However, the introduction of a heat pump system is likely to result in higher maintenance costs.

Hauer and Fischer (2011) found that introducing new drying technology in the form of an open absorption system would yield an improvement of $70 \mathrm{kWh}$ per year. When Bosch introduced zeolite as the absorption material in the drying cycle in their dishwashers, they published their concept as an innovative first mover and claimed a $25 \%$ reduction in electricity use during the drying stage (Hauer and Fischer 2011). Starting with a dishwasher with energy label B, the energy label of the final Bosch product is $\mathrm{A}+++$ and its electricity consumption is $0.83 \mathrm{kWh} /$ cycle (Bosch 2019). This figure is in the same range as that of the Miele dishwasher presented in Table 3. 
Fig. 1 Maximum annual energy use for dishwashers with a capacity of 12 place settings marked with different energy label classes. Data for the calculations were taken from European Commission (2010)

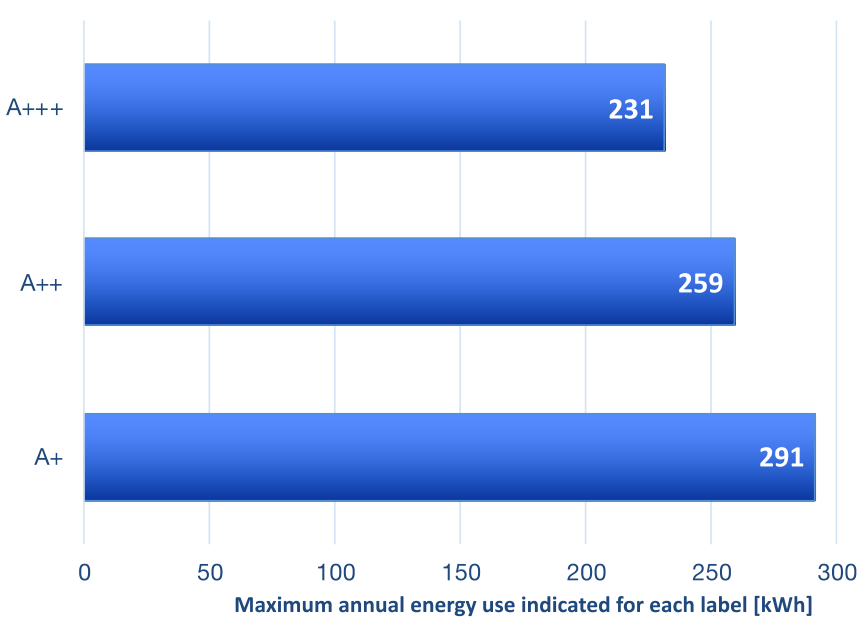

350
According to De Paepe et al. (2003), the improvement through waste water energy recovery resulted in figures corresponding to a $19-\mathrm{kWh}$ improvement in annual energy use.

\section{Consumer behaviour}

The many reports on consumer behaviour related to household appliances in the literature indicate that this is an area of impact and interest. The following topics have been frequently studied and will affect the amount of energy and water used for the chore:

- Using dishwashers compared with washing up manually

- Pre-treating dishes, mainly through rinsing

- The usual choice of program in a household

- The filling grade of the dishwasher
All these parameters will affect energy use. In this study, we relate consumer behaviour to technical development and the energy labelling system, and therefore we present the energy usage that all these behaviours could result in. It has been shown that normal consumer behaviour does not correlate with the test standard.

First, using a dishwasher is by far the most efficient way of doing the dishes. According to the figures from Stamminger (2011), who states that $0.21-\mathrm{kWh}$ energy and 9-L water are used for each place setting when washing up manually, more than twice the amount of energy would be used than if the dishes were done in an $\mathrm{A}+$ rated dishwasher. As much as $27 \mathrm{~m}^{3}$ more water per year would be used than by the dishwasher. These figures clearly show that using dishwashers is significantly better than washing up manually. Stamminger et al. (2007) also presented a study involving more than one hundred test persons in six European countries in a comparison between washing dishes by hand and in an

Table 2 Energy and water use for different programs in Electrolux ESF5533LOW

\begin{tabular}{lllllll}
\hline & Wash $\left({ }^{\circ} \mathrm{C}\right)$ & Drying rinse $\left({ }^{\circ} \mathrm{C}\right)$ & Water $(\mathrm{L} /$ cycle $)$ & Water (L/year) & Energy $(\mathrm{kWh} / \mathrm{cycle})$ & Energy $(\mathrm{kWh} /$ year $)$ \\
\hline ECO & 50 & - & 9.9 & 2772 & 0.92 & 257.6 \\
Auto & $45-70$ & - & $7-12$ & $1960-3360$ & $0.7-1.5$ & $196-420$ \\
Intensive & 70 & - & $13-15$ & $3640-4200$ & $1.4-1.6$ & $392-448$ \\
Quick wash & $60-65$ & - & 9 & 2520 & 0.8 & 224 \\
Glass & 45 & - & $13-14$ & $3640-3920$ & $0.9-1.1$ & $252-308$ \\
Rinse & - & 4 & 1120 & 0.1 & 28 \\
\hline
\end{tabular}

Temperatures in the main wash are indicated. No available data was shown for the drying preparation rinse. The program used for the energy rating is in italics (Electrolux 2017) 
Table 3 Energy and water use for different programs in Miele G 4202

\begin{tabular}{lllllll}
\hline & Wash $\left({ }^{\circ} \mathrm{C}\right)$ & Drying rinse $\left({ }^{\circ} \mathrm{C}\right)$ & Water $(\mathrm{L} /$ cycle $)$ & Water (L/year) & Energy $(\mathrm{kWh} / \mathrm{cycle})$ & Energy $(\mathrm{kWh} /$ year $)$ \\
\hline ECO & 52 & 47 & 9.7 & 2716 & 0.84 & 235 \\
Normal wash & 55 & 60 & 14 & 3920 & 1.10 & 308 \\
Intensive Wash & 75 & 60 & 15 & 4200 & 1.45 & 406 \\
Sensor wash gentle & 44 & 57 & 13.5 & 3780 & 0.90 & 252 \\
Quick wash & 40 & 45 & 11 & 3080 & 0.65 & 182 \\
Extra quiet & 46 & 64 & 10.5 & 2940 & 1.10 & 308
\end{tabular}

Temperatures in the main wash and the drying preparation rinse are indicated. The program used for the energy rating is in italics (Miele 2017)

automatic dishwashing machine. The test persons' consumption of energy, water and detergent was recorded. The tests were done in accordance with EN 50242, with the exception that the dishes were not dried in an oven before washing up. In the test, dishes were soiled with thin layers of spinach, minced meat, oat flakes, milk, margarine, tea and egg yolk. The conclusion was that dishwashers showed at least the same level of performance as almost all of the test persons, but the dishwashers used significantly less water. Additionally, huge differences in the use of resources when washing up by hand were recorded, with almost no correlation to the achieved cleaning performance. The environmental impact of detergents will be different between manual washing and dishwashers, and there is also risk that more goods are washed when the dishes can be done automatically. Even though this is a weakness in the studies, we think the main message is that using the dishwasher is the best way of doing the dishes.

Although consumers use a dishwasher, it is quite common to pre-treat the dishes before inserting them into the machine. After a meal, there are often more substantial amounts of residues left on plates. The leftovers are unavoidable rests such as bones and shells, or rests that the person disliked or did not manage to eat, and those residues that simply did not get onto the fork or spoon. How these residues are removed before the dish is put into the dishwasher is decisive for the total energy and water use. As reported by Richter (2010), there are also large differences between different countries: in Sweden $51 \%$ of consumers pre-rinse each item quickly, while this figure is as low as $10 \%$ in Germany. The average figure for Germany, Sweden, Italy and the UK is $30 \%$. The general consumer recommendation from Electrolux is do not rinse under running water. Simply scrape off the large food particles from the plates before loading the dishwasher (Electrolux 2017). This is the best possible advice because no additional water, energy or chemicals are used. The user, however, has to scrape vigorously to be left with the same small amounts of residues used in the labelling test; as explained above, residues are only brushed on during the test. Pre-rinsing in cold water can be a natural first step in order to get rid of food particles. However, as soon as the tap is opened, water use increases. If hot water is used, the energy consumption also increases. If, for example, only $5 \mathrm{~L}$ of water at a temperature of $40{ }^{\circ} \mathrm{C}$ are used to pre-rinse the dishes before running a dishwasher program, the additional amount of energy used would be $52 \mathrm{kWh}$ annually. Compared with the technical improvement suggested by Bengtsson et al. (2015) for introducing heat pump technology in the dishwasher, the amount of energy is approximately the same as for pre-rinsing the dishes.

There are often many different dishwasher programs available. In a study performed by the Swedish Energy Agency (Energimyndigheten 2017b), four different dishwashers rated $\mathrm{A}+$ or higher were tested. The average energy use of the energy labelling program was $250 \mathrm{kWh}$ and water use $2920 \mathrm{~L}$ per year. If the automatic program was used instead, energy use would rise to $340 \mathrm{kWh}$ and water use to $3980 \mathrm{~L}$ per year. This highlights the importance of choosing the right program and providing clear information to consumers. Bichler et al. (2015) examined how different programs were used in German households $(n=3836)$. The participating households ran the following programs: $18.7 \%$ used the ECO program, $17 \%$ the normal $\left(45-55^{\circ} \mathrm{C}\right)$ program, $16.9 \%$ the normal $\left(60-65^{\circ} \mathrm{C}\right)$ program, $14.5 \%$ the intensive program, $14.3 \%$ the auto program, $12.2 \%$ the quick program and $6.4 \%$ the China/delicate program. To determine how this usage would affect the energy use compared with only using the program employed during the 
energy label test, these figures were compared to those of the Miele dishwasher presented in Table 3. As the programs vary between different dishwashers, the two normal programs were assumed to be "Normal wash" and the "China/delicate" and the Auto program was assumed to equal "Sensor wash gentle". The total amount of energy used by this dishwasher through this behaviour would be $282 \mathrm{kWh}$ and $3604 \mathrm{~L}$, compared with consistently selecting the ECO program that uses only $235 \mathrm{kWh}$ and $2716 \mathrm{~L}$ per year, as presented in Table 4. The deviation accounts to $47 \mathrm{kWh}$ and $888 \mathrm{~L}$. This is more energy than what is required for changing at least one energy class in the labelling system.

There is a significant trend that in a newer dishwasher, the ECO program is slightly more frequently used than in machines older than 8 years (Boyano et al. 2017). Up to an age of 5 years, no such trend can be seen and the ECO program is used approximately for $20 \%$ of the cycles, which corresponds to the figures used in this study. This in turn means that other programs are used than the labelling program in $80 \%$ of the cases. With such low usage of the test program, the relevance of the whole labelling system must be questioned.

Finally, Richter (2011) stated that the dishwashers regularly were not filled properly. According to that study, every tenth wash cycle could be avoided. Assuming that the test procedure for the energy label gives a reasonable number of dishes for a year (amounting to $12 \times 280$ place settings) and machines are normally only $90 \%$ filled, this would mean that 31 extra programs are run in order to reach the same number of clean items. If the Miele ECO program discussed above is selected for all these wash cycles, this would entail extra energy usage amounting to $26 \mathrm{kWh}$, and if "normal consumer behaviour" is used, energy usage would increase to $31 \mathrm{kWh}$ instead.

Energy labelling system in the light of technical development and consumer behaviour

The aim of this study is to shed light on the interaction between technical developments, consumer behaviour and the energy labelling system. In Fig. 2, we aim to clarify the proportions between examples of energy increase due to how dishwashers normally are used and some technical improvements suggested in the literature. First is the reduction in the annual amount of energy required for improving the dishwashers' energy rating from $\mathrm{A}+$ to $\mathrm{A}++$, which would be a realistic goal for the dishwashers on the market. This is included in the figure so that energy reductions and increases can be related to this value, instead of a specific machine or existing technology. If the technical developments presented in this study were to be implemented, a reduction in annual energy use of between 19 and $70 \mathrm{kWh}$ would result, depending on the technology. These values are shown as reductions in Fig. 2 and are therefore negative. In relation to the increase in energy use that consumer behaviour could have on the washing cycle, the order of magnitude is approximately the same. These values are shown as positive energy increases in Fig. 2. One should also keep in mind that the figures, due to technical improvements, cannot be summarised for a single dishwasher; all improvements are studied separately in different washers. However, the figures depending

Table 4 Effects on water and energy use by choosing different programs instead of always using the ECO program

Wash $\left({ }^{\circ} \mathrm{C}\right) \quad$ Water $(\mathrm{L} / \mathrm{cycle}) \quad$ Energy $(\mathrm{kWh} / \mathrm{cycle}) \quad$ Frequency of programs based on average consumer behaviour (Bichler et al. 2015)

\begin{tabular}{|c|c|c|c|c|}
\hline$E C O$ & 52 & 9.7 & 0.84 & $18.7 \%$ \\
\hline Normal wash & 55 & 14 & 1.10 & $17 \%+16.9 \%$ \\
\hline Intensive Wash & 75 & 15 & 1.45 & $14.5 \%$ \\
\hline Sensor wash gentle & 44 & 13.5 & 0.90 & $6.4 \%+14.3 \%$ \\
\hline Quick wash & 40 & 11 & 0.65 & $12.2 \%$ \\
\hline \multirow[t]{2}{*}{ Extra quiet } & 46 & 10.5 & 1.10 & - \\
\hline & & Water (L/year) & Energy (kWh/year) & \\
\hline Total use based on consumer behaviour & & 3604 & 282 & \\
\hline Total use with ECO program & & 2716 & 235 & \\
\hline
\end{tabular}

The total usage is based on 280 wash cycles per year. Data on the different programs are from Miele G 4202 (Miele 2017) 
Maximum reduction required for changing the label $\mathrm{A}+$ to A++

Improvements suggested by De Paepe (2003)

Improvements suggested by Hauer and Fischer (2011)

Improvements suggested by Bengtsson et al. (2014)

Energy increase due to pre-rinsing with 5 litres water heated to $40^{\circ} \mathrm{C}$

Energy increase due to the usage of different programs

Energy increase correlated to not filling the dishwasher

Fig. 2 Possible energy reductions through technical improvements suggested in the literature compared with energy increases due to factors involving consumer behaviour. The maximum

on consumer behaviour can be summarised depending on how the washer is used.

The purpose of the energy label is to guide consumers as well as to drive technical developments to create a more sustainable community. Since the introduction of the energy label, the energy efficiency of appliances has increased significantly, meaning it is a good tool. At this point, the most obvious efficiency improvements have been made and about $40 \%$ of the dishwashers available on the Swedish market already have the best energy rating (A+++). This is higher than in many other countries where the market share of dishwashers with $\mathrm{A}+++$ is lower. It is reasonable to believe that in a couple of years, these markets will have the same share of A+++ dishwashers as Sweden. We identify at least two problems for further development towards a sustainable community, when this high share is reached.

The first of these problems concerns the effect of the labelling system on technical developments. As the rating is determined for a specific program, this program is "optimized" to work well for the standard test. However, the test probably does not correspond to the standard procedure in ordinary households. As discussed above, the amount of particles is often a problem as the dishwasher uses very little water. This could be a reason why

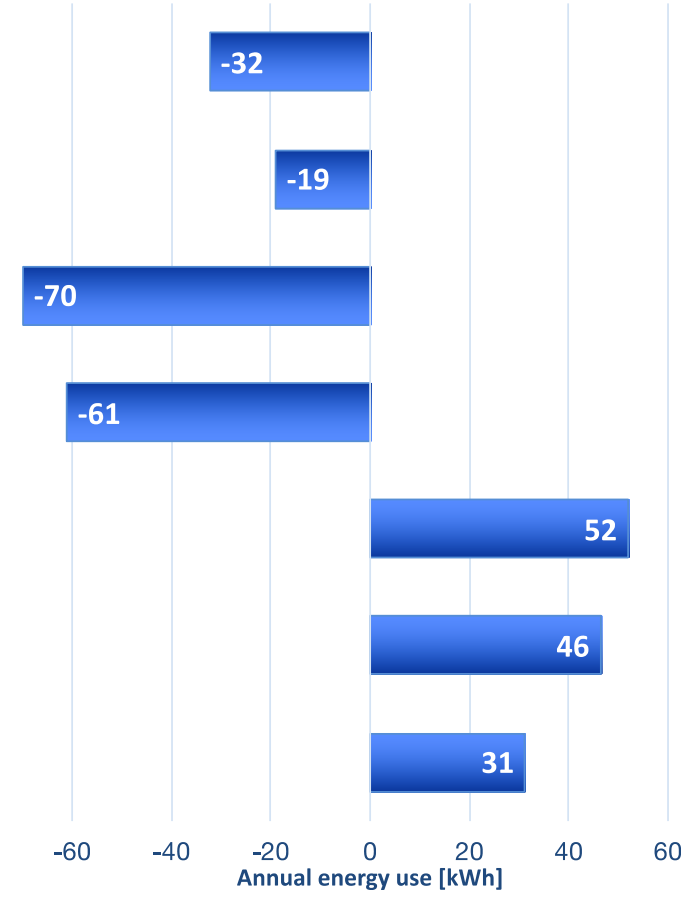

reduction required to improve the energy rating from $\mathrm{A}+$ to $\mathrm{A}++$ is shown as a comparison

consumers rinse the plates instead of following the instructions to scrape off residues. The relation between the test procedure and consumer behaviour is important to keep in mind if technical developments are to be implemented that will actually have substantial effects in households. Producers must also provide clear information regarding the energy usage of different programs and how the dishwasher should be used. This is not clear, as we saw in this study, and the deviation between different programs is considerable. For example, if a consumer consistently chooses the normal program instead of the ECO program on the Miele dishwasher (Miele 2017), water use would increase by $44 \%$ and energy use by $62 \%$. The difference between the ECO program and the intensive wash program is even greater; water use would increase by 55\% and energy use by $73 \%$ if the second of these is selected. There is a trend that the manufacturers give the programs different symbols; however, there is still a need for the consumer to study the manual carefully in order to understand the difference between the programs.

This leads to the second problem, namely the information provided to consumers regarding the energy label and how the dishwashers should be used in order to be the most energy efficient and use the lowest amount of water. A consumer can easily increase energy 
usage by $50 \%$ without being aware of doing so. As mentioned in the literature, the increased time the ECO program runs does not indicate low energy use to a consumer (Hook et al. 2018). Consumers often associate a long program running time with higher energy use.

Our suggestion is to strengthen a holistic approach to the development of products for a more sustainable community. It is important that the consumer perspective is properly considered in labelling and technical developments as pointed out by Boyano et al. (2017). One improvement would be to introduce a label for the entire dishwasher involving all programs. This is especially important as Boyano et al. (2017) present that $87 \%$ of the consumers believe that the label covers more than one program. Another development could be to reduce the number of advanced programs and work more with atomizing the machine using sensors to indicate the amount of particles, etc. in order to optimise washing while using as little energy and water as possible. This is in agreement with Brückner and Stamminger (2015), who suggest that further work is needed on the automatic program. The information provided to consumers and the education of consumers are very important aspects. As dishwashers are becoming increasingly energy efficient, all "misuse" from consumers will have a relatively greater effect on the total energy use.

Today it is, in accordance with the labelling system, possible to have special settings in the ECO program activated when the inlet water temperature is $15^{\circ} \mathrm{C}$ as used in the test standards. At any other inlet water temperature, the dishwasher can use more water or energy than displayed in the energy label. Such an optimization is not in accordance with the idea of the labelling system.

\section{Recommendations}

Most importantly, encourage the use of dishwashers because they use much less energy compared with washing up manually. Consumers should be aware of the most environmentally friendly alternative, and consumer education and information are important success factors. Manufacturers play an important role by informing and educating consumers to act in more environmentally friendly ways.

We furthermore present the following recommendations for the development of the labelling tests:

- The capacity to rinse off and separate the particles should be included in the labelling test. All manufacturers should recommend that consumers scrape off food residues instead of using water to pre-rinse dishes.

- It should be mandatory to present the energy use and the fresh water usage for all programs.

- Update the energy label to include a program that involves the sensors and a considerable amount of food particles that can be difficult to rinse.

- It should not be allowed to have special settings when the water inlet temperature is $15^{\circ} \mathrm{C}$ and have other settings at other temperatures.

Funding Information Open access funding provided by Karlstad University.

\section{Compliance with ethical standards}

Conflict of interest The authors declare that they have no conflict of interest.

Open Access This article is licensed under a Creative Commons Attribution 4.0 International License, which permits use, sharing, adaptation, distribution and reproduction in any medium or format, as long as you give appropriate credit to the original author(s) and the source, provide a link to the Creative Commons licence, and indicate if changes were made. The images or other third party material in this article are included in the article's Creative Commons licence, unless indicated otherwise in a credit line to the material. If material is not included in the article's Creative Commons licence and your intended use is not permitted by statutory regulation or exceeds the permitted use, you will need to obtain permission directly from the copyright holder. To view a copy of this licence, visit http://creativecommons.org/licenses/by/4.0/.

\section{References}

Abdessalem, T., \& Labidi, E. (2016). Economic analysis of the energy-efficient household appliances and the rebound effect. Energy Efficiency, 9(3), 605-620. https://doi.org/10.1007 /s12053-015-9387-6.

Bengtsson, P., \& Eikevik, T. (2016). Reducing the global warming impact of a household heat pump dishwasher using hydrocarbon refrigerants. Applied Thermal Engineering, 99, 12951302. https://doi.org/10.1016/j.applthermaleng.2016.02.018.

Bengtsson, P., Berghel, J., \& Renström, R. (2015). A household dishwasher heated by a heat pump system using an energy storage unit with water as the heat source. International Journal of Refrigeration, 49, 19-27. https://doi.org/10.1016 j.ijrefrig.2014.10.012.

Bichler, S., Gorny, S., Seifert, M., Kessler, A., \& Stamminger, R. (2015). How to improve sustainability and environmentally friendly behaviour in automatic dishwashing? Example: Germany. Tenside Surfactants Detergents, 52(5), 340-350. https://doi.org/10.3139/113.110384. 
Bosch (2019). Bosch SMV68TD06G, Serie | 6 Fully-integrated dishwasher $60 \mathrm{~cm}$. BSH Home Appliances Ltd. https://www. bosch-home.co.uk/product-list/dishwashers/built-indishwashers/built-in-dishwashers-60cm-width/SMV68TD06 G\#/TabsTogglebox=section-technicalspecs/Togglebox=1051994369/Togglebox=1118313654/. Accessed 2019-12-09.

Boyano, L. A., Moons, H., Villanueva Krzyzaniak, A., Graulich, K., Rüdenauer, Alborzi, F., Hook, I., \& Stamminger, R. (2017). Ecodesign and energy label for household dishwashers. EUR 28645 EN. https://doi.org/10.2760/024232.

Brückner, A. \& Stamminger, R. (2015). Consumer-relevant assessment of automatic dishwashing machines by a new testing procedure for "automatic" programmes. Energy Efficiency, 8(1), 171. https://doi.org/10.1007/s12053-014-9284-4.

Conrady, T., Kruschwitz, A., \& Stamminger, R. (2014). Influencing the sustainability of washing behavior by using motivational interviewing. Energy Efficiency, 7(2), 163-178. https://doi.org/10.1007/s12053-013-9215-9.

De Paepe, M., Theuns, E., Lenaers, S., \& Van Loon, J. (2003). Heat recovery system for dishwashers. Applied Thermal Engineering, 6, 743.

Edenhofer, O., Pichs-Madruga, R., Sokona, Y., Minx, J. C., Farahani, E., Kadner, S., Seyboth, K., Adler, A., Baum, I., Brunner, S., Eickmeier, P., Kriemann, B., Savolainen, J., Schlomer, S., von Stechow, C., \& Zwickel, T. (Eds.). (2015). Climate change 2014: mitigation of climate change; summary for policymakers technical summary; part of the working group iii contribution to the fifth assessment report of the intergovernmental panel on climate change. Geneva, Switzerland: Intergovernmental Panel on Climate Change.

Electrolux (2017). ESF5533LOW Bruksanvisning. Electrolux. https://www.electrolux.se/support/user-manual-search/ [2019-07-12].

Energimyndigheten (2017a). Energiläget 2017. No. ET 2017:12.

Energimyndigheten (2017b). Diskmaskiner. http://www. energimyndigheten.se/tester/tester-a-o/diskmaskiner. Accessed 15 Nov 2018.

Energimyndigheten (2019). Ny energimärkning från 2021. https://www.energimyndigheten.se/energieffektivisering/jag-arsaljare-eller-tillverkare-av-produkter/ekodesign-energimarkningoch-ce-markning/energimarkning/ny-energimarkning/ [201910-8].

European Commission (2010). Commission delegated regulation (EU) no 1059/2010. Official journal of the European Union, 16.

European Commission (2016). Communication from the commission to the European parliament and the council. Brussels. No. $\operatorname{COM(2016)~} 110$ final. https://eur-lex.europa.eu/legalcontent/EN/ALL/?uri=CELEX:52016DC0110. Accessed 25 Mar 2019.

European Commission (2018). Commission delegated regulation (EU), supplementing regulation (EU) 2017/1369 of the European Parliament and of the council as regards energy labelling of household dishwashers and repealing commission delegated regulation (EU) no 1059/2010. Brussels. http://www.energimyndigheten. se/globalassets/energieffektivisering/produkter-med$\mathrm{krav} /$ diskmaskiner-hushall/dishelact17oct2018towto eu612_en_1_1.pdf. Accessed 25 Mar 2019.

Gustavsberg AB (2017). Flödesdiagram för blandare | Villeroy \& Boch Gustavsberg. https://www.gustavsberg.com/se/skotsel-och- support/for-proffset/flodesdiagram-for-blandare/. Accessed 2019-01-10.

Ha, H.-Y., \& Janda, S. (2012). Predicting consumer intentions to purchase energy-efficient products. Journal of Consumer Marketing, 29(7), 461-469. https://doi.org/10.1108 /07363761211274974.

Hauer, A., \& Fischer, F. (2011). Open adsorption system for an energy efficient dishwasher. Chemie Ingenieur Technik, 83(1-2), 61-66. https://doi.org/10.1002/cite.201000197.

Hook, I., Schmitz, A. \& Stamminger, R. (2018). Dishwashing behaviour of European consumers with regard to the acceptance of long programme cycles, Energy Efficiency, 11, 1627-1640. https://doi.org/10.1007/s12053-017-9539-y.

Hubbuch, M., \& Goodall, K. G. (1999). Amount and composition of soils in German dishwashers. Composition to standard test method. SÖFW Journal - Seifen Öle Fette Wachse, 125, 14-20.

Kim, J., Park, Y., Yun, C., \& Park, C. h. (2015). Comparison of environmental and economic impacts caused by the washing machine operation of various regions. Energy Efficiency, 8(5), 905-918. https://doi.org/10.1007/s12053-015-9333-7.

Miele (2017). Customer information. https://www.miele.co. uk/domestic/customer-information-385.htm\#p510. Accessed 15 Mar 2017.

Ölander, F., \& Thøgersen, J. (2014). Informing versus nudging in environmental policy. Journal of Consumer Policy, 37(3), 341-356. https://doi.org/10.1007/s10603-014-9256-2.

Olsson, M. \& Karlsson, R. (2015). Råd\&Rön - Den stora diskkampen. Råd\&Rön. https://www.radron.se/tester/vitvaror\%2D\%2 Dhushallsmaskiner/handdisk-vs-diskmaskin/ [2018-11-15].

Pakula, C., \& Stamminger, R. (2015). Energy and water savings potential in automatic laundry washing processes. Energy Efficiency, 8(2), 205-222. https://doi.org/10.1007/s12053014-9288-0.

PriceRunner Sverige (2019). Diskmaskiner - Jämför priser på PriceRunner Sverige. PriceRunner Sverige. https://www. pricerunner.se/cl/13/Diskmaskiner [2019-01-10].

Richter, C. P. (2010). Automatic dishwashers: efficient machines or less efficient consumer habits? International Journal of Consumer Studies, 34(2), 228-234. https://doi.org/10.1111 j.1470-6431.2009.00839.x.

Richter, C. P. (2011). Usage of dishwashers: observation of consumer habits in the domestic environment. International Journal of Consumer Studies, 35(2), 180-186. https://doi. org/10.1111/j.1470-6431.2010.00973.x.

Russo, A. C., Rossi, M., Germani, M. \& Favi, C. (2018). Energy label directive: current limitations and guidelines for the improvement. Conference paper, In Procedia CIRP. Presented at the Procedia CIRP, Elsevier B.V., (69), 674 679. https://doi.org/10.1016/j.procir.2017.11.136.

Schmitz, A., \& Stamminger, R. (2014). Usage behaviour and related energy consumption of European consumers for washing and drying. Energy Efficiency, 7(6), 937-954. https://doi.org/10.1007/s12053-014-9268-4.

Stadelmann, M., \& Schubert, R. (2018). How do different designs of energy labels influence purchases of household appliances? A field study in Switzerland. Ecological Economics, 144, 112123. https://doi.org/10.1016/j.ecolecon.2017.07.031.

Stamminger, R. (2011). Modelling resource consumption for laundry and dish treatment in individual households for various consumer segments. Energy Efficiency, 4(4), 559-569. https://doi.org/10.1007/s12053-011-9114-x. 
Stamminger, R., Elschenbroich, A., Rummler, B. \& Broil, G. (2007). Washing-up behaviour and techniques in Europe. HuW, Wissenschaftlicher Beitrag, 1, 31-40.

Stawreberg, L., \& Wikström, F. (2011). Does the energy labelling system for domestic tumble dryers serve its purpose? Journal of Cleaner Production, 19(12), 1300-1305. https://doi. org/10.1016/j.jclepro.2011.03.016.

Vivian, S., Haslam, K., Soldner, M., \& Sangster, M. (2011). Assessment of European energy and carbon profiles of manual and automatic dishwashing. International Journal of Consumer Studies, 35(2), 187-193. https://doi. org/10.1111/j.1470-6431.2010.00986.x.

Publisher's note Springer Nature remains neutral with regard to jurisdictional claims in published maps and institutional affiliations. 